\title{
Historic, Contemporary, and Future Effects of Information and Communication Technologies (ICT) on People with Impairments
}

\author{
Geoff BUSBY \\ British Computer Society Disability Group \\ "Geoff Busby" < disability.grp@bcs.org.uk>
}

"Particularly with the invasive technologies, there are real ethical questions that we cannot ignore.... These kinds of technologies will soon be here and will be applied, and we will not have thought through the consequences. We need to do more thinking."

\section{THE HISTORICAL CONTEXT: WHAT HAS HAPPENED OVER THE PAST FIFTEEN YEARS}

When did information and communication technologies begin to impact on people with impairments, and how? Basically, it all began with Apple. The company was very effective, working with community groups and with disability groups, particularly on the west coast of the United States. It was the first company to have a department specially set up to address accessibility and people with impairments.

In Britain in the 1980s, the lead was taken by the BBC computer. The $\mathrm{BBC}$ was very dominant in the educational area, and it provided a lot of specialist software. The BBC was introduced into many schools in England, whereas in Scotland it was the Apple Macintosh that had the lead. Historically, the IBM personal computer then came along (but the work that IBM did on accessibility and disability was chiefly for its own employees, and on training). Then came Microsoft, and Apple took a nosedive. Microsoft took on much of Apple's software. 
IBM's achievements in the United States had more to do with providing information about where to get equipment for persons with special needs, and any special interfaces needed. This work was based in Atlanta, Georgia. Microsoft, in contrast now has 37 people employed in its Unit in Seattle, which is a very big commitment. Microsoft does a lot of work on accessibility, tapping into the skills of people with disabilities. People with disabilities are involved in beta-testing and in focus groups.

Why is Microsoft so good? The company's software has the access features that are already in-built. That all stems from the 37 people who work in Seattle, at least one of whom used to work previously for Apple. The front end of Word, for example, looks like an Apple, but it doesn't matter what technology you have, you have to change people's mindsets!

It is important to emphasise just how important interfaces are. Laptops, palmtops, telecommunications, and WAP: this is what can turn an impairment into a disability!

Since those early technology days, there has come convergence, the Net, and many forms of new ideas and new technologies. Equally, in terms of legislation, we have seen the Americans with Disabilities Act, the United Kingdom Discrimination Disability Act, and new areas of legislation in other European member states and in OECD countries like Australia and Canada. There is currently no overall European policy, but such policy is needed.

\section{THE CONTEMPORARY CONTEXT - SOME SOCIAL AND ETHICAL CONSIDERATIONS}

There are different models of disability: the medical and the social. It is particularly important that the information and communications technologies industry follows the social model. In it lies the creation of markets and potential income.

Currently you have to talk about computer-literate people with disabilities - including the older generation. There are now senior citizens who grew up with computer technology: we see this every day of our lives. Fifteen years ago, older people would not look at technology. Now, if you go to what in the United Kingdom is called 'adult education' you see a lot of older people - people who are $60+$ or $65+$ - really trying to take information technology on board, in day classes and in evening classes. There are a lot of retired people who are taking computer courses in basic word processing and email use, for example. They are no longer scared - it's not taboo. It's the way the world now is! 
For example, eCommerce is becoming a useful facility particularly for older people and people with impairments who, in common with the rest of society, are beginning to use it.

There is far greater attention to web accessibility. What are the criteria for web accessibility? You name it, we have it. Even the Labour Party was online during the last election in the United Kingdom. It is increasingly likely that people who design web pages will have to comply with the Americans with Disability Act and the United Kingdom Disability Discrimination Act. In 2002, all web sites have got to be accessible.

The British Computer Society Disability Group receives a lot of questions from people who are designing web pages. The United Kingdom government does not have a department which can help with web accessibility. Anyone who is in a government department and who wishes to start up a website, does not receive any help. But there are guidelines like World Wide Web Consortium and tools like Bobby which will allow you to check the accessibility.

One question to ask is: are we moving to a situation of total inclusion or to social exclusion? The idea is to get more things accessible, and to create more time for people. But we don't know whether that will work. It is sometimes easier to pop down to the shops or go to companies and to ask the personnel to help you.

There are now a lot more online security checks. You used to be known to your local bank. However, there has recently been a mass of online fraud, and levels of security are increasing. You cannot just phone up the bank, now you need to name your first school or your favourite historical date, or the second, third, and fifth letter of your password - items that are relevant only to you. If you have dyslexia, what hope have you got! There surely must be data showing that this is not ethical.

My personal fear is that technology will be used as a vehicle for compliance - and to avoid making public services and public buildings accessible. If you can provide services through technology, you can perhaps avoid the need to make buildings accessible.

Turning to education and training at all levels: will that really become the same? Institutions claim that they are open to everyone because their courses are online. There needs to be both a concept and a culture of accountability.

Older people are forced to use telephone banking: it is becoming more dominant. We are definitely seeing changes in people's use of technology. But rather than telephone banking, what about the use of digital television? You don't really need computers as such. Sky TV is already producing interactive television.

Now, we have legislation like the Disability Discrimination Act in the United Kingdom. There is also important civic and equal rights legislation 
for example in Australia and Canada, besides the very famous case of the United States of America and its Disability Discrimination Act. What is needed is to take a look at the Americans with Disabilities Act and also the Disability Discrimination Act, and to see how they are impacting on the lives of people with disabilities.

Where is Europe on all this? For example, the eEurope action plan 2002 focuses on inclusion and participation through web accessibility, design-forall, centres for excellence, and standardization. People say that mainland Europe is more socially conscious. But if you look at what has happened in the United States and in the United Kingdom, it is more advanced. To my mind, Europe is like America in so far as it has lots of (member) states that make legislation. There is both European-wide, and national legislation. Just as in the United States there is both federal and state legislation. So, why can't Europe have a Europe-wide piece of legislation on accessibility and disability that cuts across all the member states?

\section{INFORMATION AND COMMUNICATION TECHNOLOGIES IN THE FUTURE}

First, there are the benefits of information and communication technologies for people with impairments. If we look into our crystal ball, we see developments in ambient intelligence and ubiquitous computing, miniaturisation, smart homes, virtual reality, neural networks, artificial intelligence, neuro-surgery, and cybernetics.

As people grow older, they are much more likely to acquire impairments like mobility difficulties or cognitive impairments. The quality of life has now changed enormously for a person with Down's syndrome, who can easily live to the age of sixty. Medical science and effective diagnoses have really helped. However, the quality of life has probably not changed a lot for a person with muscular dystrophy.

In general, it is important to tackle diseases of the nervous system using information and communication technologies. Using a chip, it would probably be possible to interrupt the nervous system of someone who has cerebral palsy or Frederick's ataxia. To give you an example, my arms move a lot on their own: there is plenty of impromptu movement. The brain sends various erratic messages to the nerves and to the limbs. If it were possible to normalise such messages over a certain frequency or intervene in such a nervous system, that would lead to a vast improvement in the quality of life of an individual.

There will also be more importance placed on focusing on skills development - training young people with disabilities to go into the information and communication technologies industry. If young people with 
disabilities are empowered to use information and communication technologies, they would be all the more likely to go into the computing hardware or software industries.

In 2020, what is the potential and what are the barriers of information and communication technologies? At that time, there will be instantaneous translation and there will be computers on every wall. There will be neural networks implanted in our brains to replace any damaged areas that exist (this is already being done for people who are deaf, or who need eye implants), and chips to stem people's shakes if they have cerebral palsy.

Now, some concerns. The use of closed circuit television (CCTV) is just like George Orwell's 1984, which was spot on. The television screen is watching you. There is a constant watching of individuals occurring in the United Kingdom right now. It could be said to be good - for example in terms of physical crime control or of identifying trouble-makers - and it probably is. But it is also invading people's citizenship. Everywhere in the United Kingdom, you are being watched. But you don't even need CCTV if you have strong enough satellites! The authorities must have huge dossiers based on their global positioning systems!

The recent film Charlie's Angels used GPS-based voice technology. They were reading patterns in people's voices when they were using mobile telephones, to be able to tell where they were. If you see a technology in a film then someone somewhere is surely already using it. It would be surprising if, in the early 1960s, the very first heart transplant was really Dr. Christian Barnard's first attempt.

A man who has been blind since birth who knows me quite well, still expects me to be able to do a lot more physically than I actually can because he cannot see my disability. So, currently, a lot of people who have a disability (but not a speech impediment) would be very happy to hide behind the telephone - because the person at the other end of the phone cannot see that you are a disabled person. But as you get more audio- and video-based communications, that opportunity is going to disappear. So, you have two sides to the question. At least people will come into contact with each other, and become more aware.

By hiding behind a phone, you can avoid people's pre-conceptions. This is true for a lot of activities like telework and other interactions. A lot of disabled people who work in conventional workplaces say, 'I can't do my job because of people's attitudes towards me.' But people soon get used to working with a person with a disability. They soon see the person rather than the wheelchair. People soon get to know you.

Videophones would be very helpful in the process of getting to know people rather than letting people sit behind the telephone. Some of the most magnificent brains on the planet have a disabled body beneath them. But 
some people with impaired bodies still choose to hide away, especially academics.

We have to change people's attitudes, and we have to change attitudes in the media!

We should not lose sight of the importance of the digital divide, and of the potential that information and communication technologies can offer. But, at the end of the day, it comes down to world governments, including European governments, applying particular policies which can change people's expectations and perceptions. Wherever they are living in the world, whatever their age, people with disabilities should be able to share accessibility, empowerment, social inclusion, and independent living.

Unless you can get out of the bed in the morning, technology is not going to help you very much! But in many countries you need a great deal of support to be able to get sophisticated technologies. The public provision of services is still pretty mediocre in many countries. Commercially, most companies are not likely to do anything until governments get involved. And I think that is the real outcome!

\section{LASTLY, A WORD ABOUT IFIP}

In my opinion, IFIP seems to be built on academics, and so it is about the impact of their work in research and technological development. I would like to see more commercial involvement, but I do not think it will happen for three reasons. One, because IFIP is IFIP and it has a history of having members who are academics; two, it is difficult to change such people and to encourage them to make an impact on policy; and then, three, you have the IEEE which is much more business-oriented.

Particularly with the invasive technologies I have talked about, there are real ethical questions that we cannot ignore. It would be especially important for IFIP to look at such issues. IFIP does tend to be strong on ethics. These kinds of technologies will soon be here and will be applied, and we will not have thought through the consequences. We need to do more thinking. 